\title{
PERDAS QUANTITATIVAS E QUALITATIVAS DE COLHEDORAS COM TRILHA RADIAL E AXIAL EM FUNÇÃO DA UMIDADE DO GRÃO
}

\author{
H.S. Camolese, F.H.R. Baio ${ }^{*}$, C.Z. Alves \\ UFMS - Univ Federal de Mato Grosso do Sul, Campus de Chapadão do Sul, MS, Brasil
}

\begin{abstract}
RESUMO
A colheita é uma das principais etapas no ciclo produtivo, principalmente por poder influenciar na diminuição da produtividade do talhão, caso as regulagens da colhedora não estejam adequadas. Assim, esse trabalho visa avaliar as perdas qualitativas e quantitativas de colhedoras com trilha de fluxo radial e axial na cultura da soja, em função da variação da umidade do grão. Foram avaliadas duas colhedoras com dois diferentes sistemas de trilhas: uma axial; e outra radial. As umidades dos grãos colhidos se encontravam em duas situações: dentro da umidade recomendada; e não recomendada. Foram avaliadas as perdas quantitativas na pré-colheita, na plataforma segadora, na separação e limpeza e as perdas qualitativas pelo índice de danos mecânicos e pureza dos grãos. A perda quantitativa de grãos de soja pelo mecanismo de separação e limpeza é influenciada pelo sistema de trilha, sendo menor pelo uso da colhedora com trilha axial, independente do teor de umidade do grão de soja. Esse mesmo sistema de trilha também proporciona maior índice de pureza. A colhedora dotada com sistema de trilha radial proporciona maiores danos mecânicos aos grãos colhidos, sendo maiores quanto menor a umidade do grão de soja.
\end{abstract}

Palavras-chave: máquinas agrícolas, danos, colheita.

\section{QUANTITATIVE AND QUALITATIVE LOSSES FROM HARVESTERS WITH RADIAL AND AXIAL THRESHING SYSTEMS DEPENDING ON GRAIN MOISTURE}

\begin{abstract}
The grain harvest is one of the main stages in the crop production cycle, mainly by being able to influence the reduction of field yield, if the harvester adjustments are not appropriate. Thus, this study aims to evaluate the qualitative and quantitative grain losses from harvesters with radial and axial threshing systems in the soybean crop, according to the grain moisture variation. Two harvesters were evaluated with two threshing systems: an axial; and another radial. The grain moisture harvested was into two conditions: within the recommended moisture; and not recommended. It was made the evaluation of the quantitative losses on the pre-harvest grain, the cutter bar, the separating and cleaning mechanism and the qualitative losses by the mechanical damage index and grains purity. The quantitative grain loss on the separating and cleaning mechanism is influenced by the threshing system, being lower by use of harvester equipped with an axial threshing, regardless of soybean grain moisture. This same threshing system also provides a higher grain purity index. The harvester equipped with radial threshing system provides higher mechanical damage index, being higher the lower grain moisture.
\end{abstract}

Keywords: agricultural machinery, damage, harvest.

\footnotetext{
*fabiobaio@ufms.br
} 


\section{INTRODUÇÃO}

A cultura da soja é responsável pela ocupação de uma área de 30,14 milhões de hectares, com uma produção estimada em 85,66 milhões de toneladas no Brasil (CONAB, 2014), representando $30 \%$ do PIB da agricultura brasileira (CICARELLI et al., 2013). A colheita é uma das etapas de maior importância na produção de grãos, por se referir a de retirada do produto final do campo, podendo diminuir a qualidade do produto colhido. Na região dos cerrados é realizada a colheita pela maioria dos agricultores entre os meses de dezembro a fevereiro, período caracterizado por ser chuvoso. Esse fato impõe uma pressão sobre o agricultor, forçando-o muitas vezes a colher o produto agrícola em uma condição de umidade não ideal para disponibilização da área para um novo ciclo produtivo.

No mercado dispomos de colhedoras com dois principais sistemas de trilha: colhedoras de fluxo radial; e de fluxo axial. CUNHA et al. (2009) relatam que as colhedoras de fluxo axial podem produzir efeitos diferenciados na qualidade fisiológica do material a ser utilizado como semente. É praticamente impraticável a eliminação de todas as perdas. AGUILA et al. (2011) afirmam sobre a necessidade da redução das perdas à um mínimo para que o lucro seja maior. As perdas na colheita são influenciadas por fatores inerentes à cultura com a qual se trabalha e/ou fatores relacionados à colhedora. CHIODEROLI et al. (2011) ao determinarem as perdas quantitativas durante a colheita na cultura da soja, observaram que a qualidade da operação de colheita e as regulagens da colhedora foram dependentes da velocidade de deslocamento da máquina. De acordo com AGUILA et al. (2011), a maior percentagem de perdas pode ser relacionada à má regulagem da máquina, principalmente no mecanismo de corte e alimentação (80 a 85\%). SCHANOSKI et al. (2011) ao avaliarem as perdas na plataforma segadora, nos sistemas de trilha e de limpeza e as perdas totais na colheita mecanizada de soja, observaram que a umidade do ar, a falta de treinamento dos operadores e as deficiências na manutenção e regulagens, foram os fatores mais importantes na definição das perdas.

Segundo MARCONDES et al. (2010), a colheita realizada pela colhedora com trilha de fluxo axial resultou em sementes de soja de melhor qualidade fisiológica, em menores percentuais de sementes quebradas e em maior pureza, comparativamente à colhedora com sistema de trilha de fluxo radial. HOLTZ \& REIS (2013) observaram que existe uma dinâmica das perdas na colheita de soja sob a influência da umidade e temperatura do ar, que é refletida na umidade da palha, reportando a condição de que quanto menor a umidade da palha, maior a perda de grãos nos mecanismos de corte e alimentação, e que quanto maior a umidade, maiores as perdas de grãos na trilha. CUNHA et al. (2009) afirmaram que a colhedora com trilha axial, nas velocidades de 6 e $8 \mathrm{~km} \mathrm{~h}^{-1}$ apresentaram menor porcentagem de injúrias em comparação à colhedora radial. Quando comparados os sistemas de trilha, SILVA et al. (2004) demonstram que foram encontradas diferenças significativas para as médias de grãos perdidos, sendo que as colhedoras de fluxo axial apresentaram menores perdas, enquanto que para as colhedoras de fluxo radial as perdas foram $29 \%$ superiores, estando no nível aceitável para colheita de milho.

Para PINHEIRO \& PINHEIRO (2012), a colheita de soja sendo realizada no sentido transversal ao plantio aumenta a debulha de vagens. Isso resulta em um impacto direto do molinete com o terço superior dessas plantas, ocasionando a abertura das vagens. Segundo a EMBRAPA (2013), a umidade inadequada dos grãos no momento da colheita é um dos fatores que afeta a eficiência da colheita, sendo os danos mecânicos minimizados quando essa operação é 
realizada com o teor de umidade entre 13 a $15 \%$.

Constatam-se poucos estudos relacionados às perdas na colheita com relação ao aumento do teor de umidade dos grãos, principalmente quando se coloca nessa equação a variação de elementos de

\section{MATERIAL E MÉTODOS}

O ensaio foi conduzido na Fazenda Cristalina, localizada nas coordenadas $-18^{\circ}$ $36^{\prime} 24,8^{\prime}$ ' latitude Sul e $52^{\circ} 51^{\prime} \quad 47^{\prime}$ ' longitude Oeste, localizada no município de Chapadão do Céu-GO. Essa propriedade possui duas colhedoras combinadas de grãos com sistemas de trilha por fluxo axial John Deere 9750 STS $(640 \mathrm{~h})$; e por fluxo radial New Holland TC 5090 (82 h). As colhedoras foram operadas por profissionais com mais de cinco anos de experiência. Em todas as repetições experimentais, as colhedoras foram posicionadas lado a lado durante o trajeto, ou seja, ao final da plataforma de uma colhedora se iniciava a plataforma da outra. O talhão cultivado com soja foi semeado com a variedade SYN RR 1059 (V - TOP), a qual possui ciclo precoce e que obteve a produtividade média de 2.880 $\mathrm{kg} \mathrm{ha}^{-1}$. A densidade de semeadura foi de 15 sementes $\mathrm{m}^{-1}$, com espaçamento entre fileiras de $0,45 \mathrm{~m}$ e população aproximada de 334 mil plantas ha ${ }^{-1}$. A variação do teor de umidade dos grãos foi possível pela colheita em dias distintos: a primeira colheita foi realizada com o teor de umidade dos grãos maior do que o recomendado, simulando sua antecipação em função da pressão de instalação de um próximo ciclo agrícola; e a segunda quando se aguardou pelo teor de umidade dos grãos, indicado pela EMBRAPA (2013). Foram realizadas avaliações pelas análises das perdas pré-colheita, perdas na plataforma segadora, perdas na separação e limpeza, perdas totais (SILVEIRA, 2001), assim como a análise de pureza e índice de danos mecânicos (RAS, 2009).

As velocidades de deslocamento das colhedoras medidas em campo foram máquinas, como o sistema de trilha das colhedoras. Dessa forma, o presente trabalho visa avaliar as perdas qualitativas e quantitativas de colhedoras com trilha de fluxo radial e axial na cultura da soja, em função da variação do teor de umidade dos grãos.

de $4,6 \mathrm{~km} \mathrm{~h}^{-1}\left(1,28 \mathrm{~m} \mathrm{~s}^{-1}\right)$ para TC $5090 \mathrm{e}$ $7,6 \mathrm{~km} \mathrm{~h}^{-1}\left(2,11 \mathrm{~m} \mathrm{~s}^{-1}\right)$ para a 9750 STS. Essas velocidades foram selecionadas de acordo com as capacidades de trilha das máquinas (colhedora de trilha axial possui maior capacidade de manipulação da massa vegetal em trilha) e recomendação dos fabricantes para a situação de campo sob avaliação. $O$ processo de colheita dessas máquinas na mesma velocidade de deslocamento não seria condizente com a realidade dessa aplicação em campo.

A área amostral foi determinada por um retângulo estaqueado e delimitado por fita referente ao comprimento da plataforma segadora de cada colhedora em relação a $1 \mathrm{~m}$ de largura. Obteve-se 9,15 m de plataforma da JD 9750 STS e 7,62 $\mathrm{m}$ da NH TC 5090, resultando em uma área amostral de 9,15 $\mathrm{m}^{2}$ e 7,62 $\mathrm{m}^{2}$, respectivamente. CÂMARA et al. (2007) mensuraram que quanto maior a área amostral na avaliação da perda total, menor o coeficiente de variação entre as amostras, entretanto, manteve-se o comprimento equivalente em cada plataforma para que os resultados das perdas parciais fossem comparáveis entre si.

As quantificações das perdas précolheita foram contabilizadas pelos grãos na superfície do solo que passaram por deiscência natural. As perdas da plataforma foram obtidas pelos grãos que ficaram abaixo da plataforma segadora, grãos derrubados pela vibração da barra segadora ou trilhados pelo molinete ou por plantas arrastadas pelo movimento do molinete. A amostragem dos grãos das perdas da plataforma foi realizada após o deslocamento da colhedora para trás (ré), dentro da área amostral estabelecida 
anteriormente. A perda total foi contabilizada pelos grãos e/ou vagens não trilhadas e recolhidas na área amostral que ficaram na superfície do solo após a passagem da colhedora. A diferença entre as perdas pré-colheita somadas as perdas na plataforma segadora em relação as perdas totais resultaram nas perdas do sistema de separação e da limpeza.

Para a análise de pureza foram amostrados $500 \mathrm{~g}$ de grãos retirados do tanque graneleiro da colhedora, referente à passagem da máquina em cada repetição. $\mathrm{O}$ índice de pureza foi determinado conforme RAS (2009). Nas quantificações das injúrias mecânicas, danos e impurezas, foram amostrados $250 \mathrm{~g}$ em cada repetição. Essas amostras foram levadas a estuda com temperatura controlada em $105^{\circ} \mathrm{C}$ durante as $24 \mathrm{~h}$. As quantificações foram padronizadas em umidade de $13 \%$. O índice de danos mecânicos foi obtido pala

\section{RESULTADOS E DISCUSSÃO}

Na primeira colheita, as amostras dos grãos das colhedoras apresentaram média de $19,8 \%$ de teor de umidade na massa de grãos, variando entre 18,1 a 20,9 $\%$. $\mathrm{Na}$ segunda colheita as amostras expressaram média de $15,3 \%$ de teor de umidade dos grãos, variando entre 14,2 a $15,7 \%$.

Houve interação $(p>0,05)$ entre os fatores sistema de trilha e umidade nas análise dos grãos inteiros em relação aos quebrados. Também foram contabilizados como danos mecânicos aquelas partes de grãos separados pelos seus cotilédones ou grão partidos. A umidade dos grãos das amostras retiradas do tanque graneleiro foi mensurada em campo por um medidor de umidade Agrologic, modelo portátil AL101.

O experimento foi conduzido em um delineamento experimental em blocos ao acaso em um esquema fatorial $2 \times 2$, sendo dois sistemas de trilha (radial e axial) e dois teores de umidades dos grãos no momento da colheita (inadequada e adequada). Foram amostradas cinco repetições por tratamento. As médias dos tratamentos foram comparadas pelo teste de Tukey a 5\% de probabilidade, utilizando o programa livre ASSISTAT (SILVA \& AZEVEDO, 2002).

análises das perdas quantitativas no sistema de separação e limpeza da colhedora, pureza e danos mecânicos (Tabela 1). As perdas quantitativas na précolheita não se diferenciaram estatisticamente em relação às condições de umidade do grão e ao fator sistema de trilha, já que é independente da colhedora. 
Tabela 1. Perdas parciais e totais, pureza e danos mecânicos (\%) em relação as condições de umidade dos grãos de soja (U) e pelos dois sistemas de trilha das colhedoras avaliadas (C).

\begin{tabular}{lcccccc}
\hline & $\begin{array}{c}\text { Pré- } \\
\text { colheita }\end{array}$ & Plataforma & $\begin{array}{c}\text { Separação } \\
\text { e limpeza }\end{array}$ & $\begin{array}{c}\text { Perdas } \\
\text { totais }\end{array}$ & Pureza & $\begin{array}{c}\text { Danos } \\
\text { mecânicos }\end{array}$ \\
\hline \multicolumn{7}{c}{ Colhedoras (C) } \\
\hline C_Axial & $0,05 \mathrm{a}$ & $9,92 \mathrm{a}$ & $1,21 \mathrm{~b}$ & $11,17 \mathrm{a}$ & $99,86 \mathrm{a}$ & $0,39 \mathrm{~b}$ \\
C_Radial & $0,05 \mathrm{a}$ & $4,85 \mathrm{~b}$ & $2,78 \mathrm{a}$ & $7,67 \mathrm{~b}$ & $99,02 \mathrm{~b}$ & $2,24 \mathrm{a}$ \\
\hline \multicolumn{7}{c}{ Umidade (U) } \\
\hline $19,8 \%$ & $0,05 \mathrm{a}$ & $7,33 \mathrm{a}$ & $3,24 \mathrm{a}$ & $10,61 \mathrm{a}$ & $99,63 \mathrm{a}$ & $0,94 \mathrm{~b}$ \\
$15,3 \%$ & $0,05 \mathrm{a}$ & $7,44 \mathrm{a}$ & $0,75 \mathrm{~b}$ & $8,23 \mathrm{~b}$ & $99,27 \mathrm{~b}$ & $1,69 \mathrm{a}$ \\
\hline \multicolumn{7}{c}{ Fator F $^{2}$} \\
\hline $\mathrm{F}(\mathrm{C})$ & $2,25^{\mathrm{ns}}$ & $107,72^{*}$ & $13,14^{*}$ & $29,51^{*}$ & $307,15^{*}$ & $193,69^{*}$ \\
$\mathrm{~F}(\mathrm{U})$ & $2,25^{\mathrm{ns}}$ & $0,05^{\mathrm{ns}}$ & $33,06^{*}$ & $13,70^{*}$ & $60,67^{*}$ & $31,72^{*}$ \\
$\mathrm{~F}\left(\mathrm{C}^{*} \mathrm{U}\right)$ & $0,25^{\mathrm{ns}}$ & $4,63^{\mathrm{ns}}$ & $15,04^{*}$ & $0,96^{\mathrm{ns}}$ & $34,13^{*}$ & $19,19^{*}$ \\
\hline $\mathrm{CV}(\%)$ & 12,15 & 11,44 & 37,74 & 11,83 & 0,08 & 17,56 \\
\hline
\end{tabular}

${ }^{1}$ Médias seguidas por letras distintas nas colunas, diferem significativamente entre si, a $5 \%$ de probabilidade pelo teste de Tukey. ${ }^{2}$ Pelo teste $\mathrm{F}: *$ significativo a $5 \%$ de probabilidade; ${ }^{\mathrm{ns}}$ não significativo.

A colhedora com o sistema de trilha axial obteve maiores perdas quantitativas na plataforma segadora independente das condições de umidade dos grãos. Esse fato pode ser explicado em função da velocidade de deslocamento dessa colhedora com trilha axial ter sido $65,2 \%$ maior. Contudo, essa maior velocidade de deslocamento de $7,6 \mathrm{~km} \mathrm{~h}^{-1}$ seguiu a recomendação do fabricante para as condições ambientais presentes no talhão. A maior velocidade proporciona maior impacto na barra segadora, podendo levar a maior abertura das vagens naquele instante. Altas velocidades de deslocamento também exigem uma maior velocidade angular do molinete, podendo acarretar em debulha de vagens nessa etapa. O sistema de corte e alimentação das colhedoras utilizadas possuíram as mesmas tecnologias. Houve uma evolução em vários elementos de máquinas das colhedoras combinadas ao longo do tempo, como uma maior capacidade de trilha pelos rotores axiais, além do sistema de corte e alimentação por barra segadora e molinete. No entanto, máquinas com esses avanços tecnológicos ainda são menos comercializadas, sendo que grande parte da classe produtora persiste com colhedoras de sistemas de corte, alimentação e trilha com tecnologia antiga, devido aos elevados custos de aquisição das máquinas mais modernas. As perdas referentes à plataforma equivaleram a $87,5 \%$ de todas as perdas quantitativas avaliadas no trabalho, semelhante aos resultados obtidos por PINHEIRO \& PINHEIRO (2012). SCHANOSKI et al. (2011) observaram que esse índice relativo à plataforma foi de $75 \%$. Segundo HEIFIG \& CÂMARA (2006), a velocidade angular e a posição do molinete são determinantes para acarretarem perdas. Nesse trabalho conduzido pelos autores resultou que a falta de regulagem no molinete associado com a elevada velocidade da colhedora proporcionou maior debulha na plataforma.

A Tabela 2 apresenta 0 desdobramento da interação ocorrida entre as perdas quantitativas de grãos de soja no processo de separação e limpeza em função da variação da umidade do grão e do sistema de trilha. O maior valor de perda quantitativa pelo mecanismo de separação e limpeza foi obtido pela interação entre o uso da colhedora com trilha radial colhendo na maior condição de umidade da soja. A colhedora com sistema de trilha axial não proporcionou variação significativa de perdas no mecanismo de separação e limpeza dos grãos em função 
das diferentes umidades de colheita. No entanto, a colhedora com o sistema de trilha radial quando realizou a colheita na maior umidade do grão, gerou uma perda seis vezes maior no sistema de separação e limpeza, ilustrando a necessidade das máquinas dotadas com esse sistema de trilha colherem sempre a soja na umidade recomendada pela EMBRAPA (2013). Contudo, ao colher com uma máquina dotada com o sistema de trilha axial é possível flexibilizar o momento da colheita em função de uma maior umidade do grão de soja, sem variação significativa nas perdas quantitativas do processo de separação e limpeza pela colhedora.

Tabela 2. Interação das perdas quantitativas de grãos da colhedora no mecanismo de separação e limpeza em função da variação da umidade do grão e do sistema de trilha.

\begin{tabular}{ccc}
\hline Colhedoras $(\mathrm{C})$ & Umidade a 19,8\% & Umidade a 15,3\% \\
\hline C_Axial & $1,61 \mathrm{bA}$ & $0,80 \mathrm{aA}$ \\
C_Radial & $4,87 \mathrm{aA}$ & $0,69 \mathrm{aB}$ \\
\hline Média & \multicolumn{3}{c}{1,99} \\
CV $(\%)$ & 37,74 \\
\hline
\end{tabular}

Médias seguidas por letras minúsculas distintas na coluna e maiúsculas distintas na linha diferem entre si pelo teste de Tukey a um nível de 5\% de probabilidade. DMS - Diferença Mínima Significativa para colhedoras (letras minúsculas) $=1,99 \%$; DMS para umidade (letras maiúsculas) $=1,99 \%$.

FIGUEIREDO et al. (2013) e TABILE et al. (2008) avaliando as perdas de grãos de trigo produzidas nos mecanismos internos da colhedora com sistema de trilha radial também observaram que as perdas foram maiores quando se realizou a colheita antecipada da cultura, ou seja, com alto conteúdo de umidade dos grãos. Entretanto, esses autores não avaliaram em situação comparativa uma outra colhedora com sistema de trilha axial. Já POSSIDONIO \& RUFFATO (2013), obtiveram um resultado de perdas no sistema de separação e limpeza $35 \%$ maior pela colhedora com sistema de trilha radial quando comparada com a colhedora com sistema de trilha axial, todavia, esses autores não avaliaram em situação comparativa variando a umidade do grão. HOLTZ \& REIS (2013) observaram que em momentos de maior umidade relativa do ar e com menores temperaturas no ambiente as perdas de grãos no sistema de separação e limpeza se elevaram. Essas perdas são provenientes da maior dificuldade de separação dos grãos dos restos culturais da massa vegetal, que com o aumento da umidade relativa do ar, o material vegetal absorve água do ambiente e com isso apresenta resistência de desagregação entre essa massa vegetal e os grãos no sistema de separação e limpeza.

A colhedora dotada de trilha axial proporcionou os maiores valores do índice de pureza dos grãos de soja pela variação do sistema de trilha, independente da umidade (Tabela 3). Já a colhedora dotada com o sistema de trilha radial e mesmo colhendo o grão de soja na umidade recomendada (EMBRAPA, 2013) obteve o menor índice de pureza dos grãos. Condição semelhante foi observado por MARCONDES et al. (2010), onde a colhedora dotada com o sistema de trilha axial apresentou o índice de pureza maior do que na colheita realizada pela colhedora com o sistema radial. 
Tabela 3. Interação do índice de pureza (\%) dos grãos de soja em função da variação da umidade do grão e do sistema de trilha da colhedora.

\begin{tabular}{ccc}
\hline Colhedoras (C) & Umidade a 19,8\% & Umidade a 15,3\% \\
\hline C_Axial & $99,91 \mathrm{aA}$ & $99,82 \mathrm{aA}$ \\
C_Radial & $99,35 \mathrm{bA}$ & $98,70 \mathrm{bB}$ \\
\hline Média & & 99,44 \\
CV $(\%)$ & & 0,08 \\
\hline
\end{tabular}

Médias seguidas por letras minúsculas distintas na coluna e maiúsculas distintas na linha diferem entre si pelo teste de Tukey a um nível de 5\% de probabilidade. DMS - Diferença Mínima Significativa para colhedoras (letras minúsculas) $=0,16 \%$; DMS para umidade (letras maiúsculas) $=0,16 \%$.

$\mathrm{O}$ maior índice de dano mecânico foi obtido pela colheita dos grãos na umidade recomendada pela EMBRAPA (2013) e utilizando a colhedora dotada com o sistema de trilha radial (Tabela 4). Nessa condição de umidade, o índice de dano mecânico ao grão de soja foi 6,2 vezes maior do que pelo uso de uma colhedora dotada com trilha axial. O aumento do dano mecânico poderia influenciar a taxa germinativa, inviabilizando o uso do grão como semente, assim como diminuir o tempo de armazenamento em função de injúrias no tegumento. O maior índice de dano mecânico do grão pela colheita na menor umidade poderia ser explicado pela menor flexibilidade do tegumento no momento do impacto pelo rotor de trilha. POSSIDONIO \& RUFFATO (2013) encontraram índices de danos mecânicos nos grãos pelo uso de colhedora com sistema de trilha radial e axial de $17,64 \%$ e $1,94 \%$, respectivamente.

Tabela 4. Interação do índice de dano mecânico (\%) dos grãos de soja em função da variação da umidade do grão e do sistema de trilha da colhedora.

\begin{tabular}{ccc}
\hline Colhedoras $(\mathrm{C})$ & Umidade a 19,8\% & Umidade a 15,3\% \\
\hline C_Axial & $0,30 \mathrm{bA}$ & $0,47 \mathrm{bA}$ \\
C_Radial & $1,57 \mathrm{aB}$ & $2,91 \mathrm{aA}$ \\
\hline Média & \multicolumn{3}{c}{1,31} \\
CV $(\%)$ & 17,56 \\
\hline
\end{tabular}

Médias seguidas por letras minúsculas distintas na coluna e maiúsculas distintas na linha diferem entre si pelo teste de Tukey a um nível de 5\% de probabilidade. DMS - Diferença Mínima Significativa para colhedoras (letras minúsculas) $=0,43 \%$; DMS para umidade (letras maiúsculas) $=0,43 \%$.

A colhedora equipada com o sistema de trilha axial obteve bons índices comparativos, ilustrando que houve uma evolução no sistema de trilha, separação e limpeza dos grãos entre as máquinas avaliadas. No entanto, alguns elementos das máquinas antigas não tiveram desenvolvimento e ainda persistem nas máquinas mais modernas, como a plataforma segadora. As colhedoras atuais estão sendo desenvolvidas para uma maior capacidade de processamento do material vegetal, principalmente na trilha $\mathrm{e}$ separação. 


\section{CONCLUSÕES}

As perdas quantitativas totais de grãos de soja são influenciadas principalmente pela plataforma segadora. A colhedora equipada com trilha axial possui maiores perdas totais na plataforma segadora.

A perda quantitativa de grãos de soja ocasionada pelo mecanismo de separação e limpeza é influenciada pelo sistema de trilha, quando o teor de

\section{REFERÊNCIAS BIBLIOGRÁFICAS}

AGUILA, L.S.H.; AGUILA, J.A. THEISEN, G. Perdas na colheita da cultura da soja. Pelotas: Embrapa Clima Temperado, 2011. 12p. (Embrapa Clima Temperado. Comunicado Técnico 271).

CÂMARA, F.T.; SILVA, R.P.; LOPES, A.; FURLANI, C.E.A.; GROTTA, D.C.C.; REIS, G.N. Influência da área de amostragem na determinação de perdas totais na colheita de soja. Ciência e Agrotecnologia, Lavras, v.31, n.3, p.909913, 2007.

CHIODEROLI, C.A.; SILVA, R.P.; NORONHA, R.H.F.; CASSIA, M.T.; SANTOS, E.P. Perdas de grãos e distribuição de palha na colheita mecanizada de soja. Bragantia, Campinas, v.71, n.1, p.112-121, 2012.

CICARELLI, M.; DURÃO, M.; PITA, A; NEDER, V. IBGE: Safra recorde de soja puxou PIB no $2^{\circ}$ trimestre. Agência Estado. 2013. Disponível em: < http://economia.estadao.com.br/noticias/ge ral,ibge-safra-recorde-de-soja-puxou-pibno-2-trimestre, $163388 \mathrm{e}>$ Acesso em: 24 ago. 2014.

CONAB (Companhia Brasileira de Abastecimento). Acompanhamento da safra brasileira de grãos, v.1 - Safra 2013/14, n.11 - Décimo Primeiro Levantamento, Brasília, p. 1-82, ago. 2014.

COSTA, N.P.; MESQUITA, C.M.; HENINNG, A.A. Avaliação das perdas e qualidade de semente na colheita mecânica umidade do grão de soja é maior. A colhedora com sistema de trilha axial proporciona maior índice de pureza dos grãos.

A colhedora dotada com sistema de trilha radial proporciona maiores danos mecânicos aos grãos colhidos, sendo maiores quanto menor o teor de umidade dos grãos de soja.

de soja. Revista Brasileira de Sementes, Londrina, v.1, n3, p.49-58, 1979.

CUNHA, J.P.A.R.; PIVA, G.; OLIVEIRA, C.A.A. Efeito do sistema de trilha e da velocidade das colhedoras na qualidade de sementes de soja. Bioscience Journal, Uberlândia, v.25, n.4, p.37-42, 2009.

EMPRESA BRASILEIRA DE PESQUISA AGROPECUÁRIA. Tecnologias de produção de soja. Londrina: Embrapa Soja, 2013. 265 p. (Sistemas de Produção, 16).

FIGUEIREDO, A.S.T.; RESENDE, J.T.V. MORALES, R.G.F. MEERT, L.; RIZZARDI, D.A. Influência da umidade de grãos de trigo sobre as perdas qualitativas e quantitativas durante a colheita mecanizada. Ambiência - Revista do Setor de Ciências Agrárias e Ambientais. v.9, n.2, p. 349-357, 2013.

HEIFFIG, L.S.; CAMARA; G.M.S. Soja: Colheita e perdas. Ed. Especial. Piracicaba: Serviços de produções gráficas-USP/ESALQ. 2006. 37p.

HOLTZ, V.; REIS, E.F. Perdas na colheita mecanizada de soja: uma análise quantitativa e qualitativa. Ceres, Viçosa, v.60, n.3, p.347-353, 2013.

\section{MACHADO, A.L.T. Colhedoras de fluxo axial reduzem danos às sementes. Disponível em:} $<$ www.seednews.inf.br/portugues/seed74/a 
rtigocapa74.shtml>. Acesso em: 27 ago. 2014.

MARCONDES, M.C.; MIGLIORANZA, E.; FONSECA, I.C.B. Qualidade de sementes de soja em função do horário de colheita e do sistema de trilha de fluxo radial e axial. Engenharia Agrícola. Jaboticabal, v.30, n.2, p.315-321, 2010.

PINHEIRO, P.P.; PINHEIRO, M,G. Fortuna perdida. Cultivar Máquinas. Porto Alegre, v.11, n.117, p.8-12, 2012.

POSSIDONIO, F.R.; RUFFATO, S. Axial $\mathrm{x}$ Radial. Cultivar Máquinas. Porto Alegre, v.12, n.138, p.15-19, 2013.

REGRAS PARA ANÁLISES DE SEMENTES - RAS. Ministério da Agricultura, Pecuária e Abastecimento. Brasília, 2009. 395p.

SCHANOSKI, R.; RIGHI, E.Z.; WERNER, V. Perdas na colheita mecanizada de soja (Glycine max) no município de Maripá - PR. Revista Brasileira de Engenharia Agrícola e Ambiental, Campina Grande, v.15, n.11, p.1206-1211, 2011.

SILVA, R.P.; CAMPOS, M.A.O.; MESQUITA, H.C.B.; ZABANI, S. Perdas na colheita mecanizada de milho no triângulo mineiro e Alto Paranaíba-MG. FAZU em Revista, Uberaba, v.1, n.1, p.310, 2004.

SILVA, F.A.S.; AZEVEDO, C.A.V. Versão do programa computacional Assistat para o sistema operacional Windows. Revista Brasileira de Produtos Agroindustriais, Campina Grande, v.4, n.1, p.71-78, 2002.

SILVEIRA, G.M. Máquinas para colheita e transporte. Viçosa: Aprenda Fácil, 2001. 289p.

TABILE, R.A.; TOLEDO, A.; SILVA, R.P.; FURLANI, C.E.A.; GORTTA, D.C.C.; CORTEZ, J.W. Perdas na colheita de milho em função da rotação do cilindro trilhador e umidade dos grãos. Scientia Agraria, Curitiba, v.9, n.4, p.505-510, 2008. 